\title{
Does an Avatar Motivate?
}

\author{
Mohammad Nur Azhar Mazlan, Liz Burd \\ Durham University, m.n.a.mazlan@durham.ac.uk, liz.burd@durham.ac.uk
}

\begin{abstract}
The purpose of this study is to investigate students' perceptions of their motivation to learn while possessing an avatar alongside the learning activities. The activities include attendance and accessing the course module's eLearning portal. 47 students participated in the study and were divided into two groups: an avatar group and a non-avatar group. Additionally, two research instruments were used in the study. Firstly, an avatar environment named Avatar Hall was developed to allow the students from the avatar group to view their avatars. The second instrument was a motivation inventory, which was used to identify the students' perceptions of the extent to which the presence of an avatar motivated them to learn. The results for both groups show a moderate percentage distribution of the students' perceptions of their motivation to learn and further statistical test reveal no significant difference between the two groups of students in terms of their motivation to learn.
\end{abstract}

Index Terms - Avatar, Motivation.

\section{INTRODUCTION}

The term avatar originates from the Sanskrit language, in which it refers to the incarnation or appearance of God on the earth [1]. In the context of computing, an avatar is defined as a graphical character that represents the user in another environment [1], [2], [3], [4], as used in computer games, such as the World of Warcraft (WOW), and in social networking environment such as the Second Life [5]. Moreover, [6] described an avatar as a graphical representation that is personified by computer technology.

According to [7], the use of avatars in the online environment began as early as the mid-1980s as a marketing tool, and started to appear in computer games in 1985 with Ultima IV [8]. Advancements in computing technology in the past ten years have changed the way in which avatars are represented, with users now able to manipulate representations of themselves, adding custom-built body parts and facial features to their avatars in both games and online communities [9].

Any object can become an avatar as long as it is used as a representative character by the user. It can be a controllable character, as in digital games, an icon or a textual description, such as a name [1]. [10] describes an avatar as "an interactive, social representation of a user".

An avatar representation is an identity that the user creates. [11] describes identity as a person's ability to identify him or herself with another person or character, and within a specific situation. This identification phenomenon is similar to the activity explained in [12] theory of possible selves, according to which, as cited by [12], "an individual is free to create any variety of possible selves, where it derives from individual's sociocultural and historical context and from the models, images, and symbols provided by the media and by the individual's immediate social experiences". As observed in many avatar personalisation activities, the users are free to create their avatars, using their imagination to personalise them according to the environment; for example, in games and the social networking.

Avatars have been used in many situations. According to [13], avatars exist on many web pages to represent the users in an online environment.

\section{Avatars in the Business Sector}

In the business sector, as mentioned by [14], avatars can be found in online advertising, on e-commerce sites and on vending machines, for the purpose of relaying messages and enhancing customers' purchase experience. An avatar can be used as a communication platform between the business owner and the customer, or as a virtual marketing or sales tool, where it acts in a similar way to a real-life marketing and sales executive.

As stated by [15], "an avatar serves the same purpose that any live customer service or sales representative would and can interact in real time to answer customers' questions". [15] points to a situation where in the future, businesses will be able to use avatars to represent their customers as they examine goods such as clothing, gadgets and accessories. [16] describes this as follows: "In the mall of a virtual world, for example, an avatar could try-on and try-out in front of virtual friends - real-world clothing brands. If she got rave reviews from her friends and became comfortable with the idea of wearing a particular outfit, a purchase in the real world might follow".

\section{Avatars in the Education Sector}

In the education sector, the avatar is used to represent a teacher or instructor in an online and virtual learning environment. Instruction is delivered by Computer-Based Learning (CBL), through CD or on the Web, and an avatar will play the role of a tutor in guiding learners through the learning processes.

In addition to having an avatar as a tutor or instructor, learners can also have their own avatar which allows them to experience their learning through their avatars and also to observe other avatars' activities [17]. 